\title{
Supera Stent for Management of Occlusive Popliteal Artery Disease: an Indian Experience
}

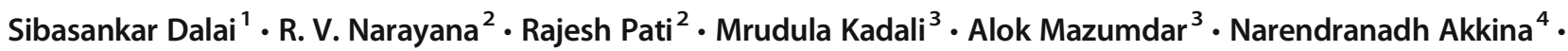 \\ Samir Kumar Panda ${ }^{5}$
}

Received: 5 August 2019 / Accepted: 8 May 2020 / Published online: 28 May 2020

(C) The Author(s) 2020

\begin{abstract}
Introduction Popliteal artery occlusion is common in elderly, smokers, and patients with diabetes, with globally rising incidence. Angioplasty and stenting are common treatment options available to manage lower limb occlusive diseases. As popliteal artery experiences high biomechanical stress, Supera stent is designed to reduce the risk of stent fractures and for better patency across the knee joint.

Aim \& Objectives The aim of this study is to evaluate the Supera stent in the management of popliteal artery occlusive disease. The objectives of this study are (1) to evaluate the efficacy of Supera stent in the management of popliteal artery occlusive disease and (2) to prove it as a relatively safe to use option.

Material \& Methods Patients who underwent stent implantation in popliteal artery were analyzed with regular/serial follow-up. Critical limb ischemia and intermittent claudication patients were included. Medical records, radiographs, and procedural data were examined. The patients were classified according to Trans-Atlantic Inter Society Consensus II criteria. The femoropopliteal lesions which were classified into TASC B and C categories were included in the study. Stents of $5 \mathrm{~mm}$ and $5.5 \mathrm{~mm}$ diameter and with various lengths were used to treat all the patients.

Results A total number of patients with tissue loss and rest pain analyzed were eighty-six and all of them were treated by implanting stents in popliteal artery. In $71.4 \%$ of cases, the lesions were found in the proximal segment of the artery. In nearly $95 \%$ of cases, technical success was achieved with the use of single stent. The primary and assisted primary patency rates at 24 months were found to be $86.04 \%$ and $95.34 \%$, respectively. Notwithstanding the stent placement at a region of high biomechanical stress, there was no case of stent fracture. The limb salvage rate was $100 \%$. The patients who died due to unrelated causes within 90 days of procedure were two.

Conclusion The present study demonstrated that Supera stent is a safe and effective procedure for treating claudication and limb ischemia due to popliteal artery disease.
\end{abstract}

Keywords Popliteal artery $\cdot$ Supera stent $\cdot$ Primary patency $\cdot$ Indian population $\cdot$ Atherosclerotic lesions

Sibasankar Dalai

sibasankar@gmail.com

R. V. Narayana

drrvnarayana2019@gmail.com

Rajesh Pati

drrajeshpati2011@gmail.com

Mrudula Kadali

mruduworld@gmail.com

Alok Mazumdar

alok_mazumdar@yahoo.com

Narendranadh Akkina

drnarendraa@gmail.com
Samir Kumar Panda

drsamirpanda@gmail.com

1 Chief of Interventional Radiology SevenHills Hospital, Visakhapatnam, India

2 Department of Neurology, SevenHills Hospital, Visakhapatnam, India

3 Department of Surgery, SevenHills Hospital, Visakhapatnam, India

Department of Orthopedics, SevenHills Hospital, Visakhapatnam, India

5 Department of Medicine, SevenHills Hospital, Visakhapatnam, India 


\section{Introduction}

Atherosclerotic lesions, with or without calcification, are a common cause of peripheral artery disease (PAD) of the lower limbs [1] and may also lead to cardiovascular mortality and amputation [1,2]. Additionally, patients often present at later stages when only limited treatment options are available [1, 3]. Some common treatment options for lower limb occlusive diseases include surgical bypass grafting, balloon angioplasty, atherectomy, and endovascular stenting. The success with self-expanding endoprostheses and angioplasty is progressing with the use of stents. Nitinol stents with laser cut or stents made of new metal alloys, drug-eluting technology, and bioabsorbable structural support system have been used in the recent times $[4,5]$.

However, although the stents give the advantage of minimal, improved durability, and shorter recovery times, the associated complications like in-stent restenosis (ISR) causing re-intervention cannot be overlooked. The ISR remains a major concern for interventional radiologists [6]. As reported in different retrospective studies, in terms of incidence of restenosis and requirement of re-intervention, bypass surgery gives better results than endovascular stenting [1, 6-8].

The Supera nitinol stent is developed to have superior strength and resistance as compared with laser cut nitinol stents, especially for occlusions close to highly mobile joints and to withstand the stressors along the knee joint $[5,9]$. Stents generally fall short for providing long-term solutions in complex lesions. The Supera stent (Abbott Vascular), a self-expanding, interwoven nitinol stent (US FDA approved in 2014), has certain advantages over the earlier available stents [10].

The optimal patency of lower extremities depends upon the artery's anatomical location. Due to the high mobility of knee joint, there are concerns for fracture, compression, or occlusion of the stents in the popliteal artery. Another risk is the ISR $[11,12]$, which is also dependent on various predictors like vessel diameter and staging of restenosis [11].

There are evidences of Supera stent use for superficial femoral artery, and femoropopliteal artery from the Western countries $[5,13]$. However, similar evidence for popliteal artery occlusions, especially in Indian population, is required. This study represents the Indian experience with Supera stent to manage popliteal artery atherosclerotic disease by analyzing its use in popliteal artery occlusion among Indian population.

\section{Methods}

This case series analysis, longitudinal, observational study was conducted from January 2015 to January 2019 in SevenHills Hospitals, Vishakhapatnam. During this period, a total of 170 patients underwent angioplasty with stenting of the lower limbs. Out of 170 patients, eighty-six patients had stents in the popliteal artery and were included in the present study. Inpatient and outpatient medical records, radiographic imaging, and procedural data were analyzed. Demographic features including age, race, gender, history of smoking or of tobacco use, continuing use of anti-coagulants, and risk factors including presence of co-morbid conditions like diabetes, hypertension, coronary artery disease (CAD), chronic obstructive pulmonary disease, hyperlipidemia, renal dysfunction (elevation of serum creatinine levels $>1.2$ at any point before or after stenting procedure), and presence of peripheral arterial disease elsewhere in the body were recorded. The American Society of Anesthesiologists Physical Status classification was used. Pre- and post-procedural creatinine and ankle-brachial indices were recorded with procedural characteristics including laterality, duration of intervention, fluoroscopy, and iodinated contrast volume.

\section{Patient Population}

Patients with intermittent and lifestyle-limiting claudication, pain at rest in the affected limb or with ipsilateral tissue loss, and with lesions in popliteal artery were included. The presence of at least one leg artery for distal runoff was an essential inclusion criterion.

However, patients with creatinine clearance $<30 \mathrm{~mL} / \mathrm{kg} /$ min, history of severe allergy to iodinated contrasts, and with significant atherosclerotic disease in aortoiliac and/or femoral territories were excluded. Pre-operative arteriography classified the lesions according to the following: (1) the TransAtlantic Inter Society Consensus II (TASC-II) 7 criteria: A, $\mathrm{B}, \mathrm{C}$, or D. The lesions which were classified into TASC B and $C$ categories were included in the study (2) type: stenosis, occlusion, dissection, or restenosis; (3) location relative to the articular line: proximal, middle, or distal; and (4) length.

\section{Definitions (Table 1)}

Primary patency, cumulative primary assisted patency, restenosis, complication, and limb salvage rates were calculated using Doppler ultrasonography (USG) imaging and findings of angiography, wherever available.

\section{Treatment}

Clopidogrel (75 mg/day) or ticagrelor $90 \mathrm{mg} /$ twice a day and aspirin $(150 \mathrm{mg})$ once a day were started at least 3 days before procedure. Clopidogrel ( $75 \mathrm{mg} /$ day) or ticagrelor $90 \mathrm{mg} /$ twice a day was stopped at 6 months. Tab ecosprin was continued lifelong. Treatment with antimicrobial prophylaxis of cefuroxime axetil $(1.5 \mathrm{~g})$ immediately before the beginning of the procedure was given. 
Table 1 Classification of femoropopliteal lesions according to TransAtlantic Inter Society Consensus II (TASC-II)

\begin{tabular}{|c|c|}
\hline Type A & $\begin{array}{l}\text { - Single stenosis } \leq 10 \mathrm{~cm} \text { in length } \\
\text { - Single stenosis } \leq 5 \mathrm{~cm} \text { in length }\end{array}$ \\
\hline Type B & $\begin{array}{l}\text { - Multiple lesions (stenosis or occlusions) each } \\
\leq 5 \mathrm{~cm} \\
\text { - Single stenosis or occlusion } \leq 15 \mathrm{~cm} \text { involving the } \\
\text { infra geniculate popliteal artery } \\
\text { - Single or multiple lesions in the absence of } \\
\text { continuous inflow for a distal bypass } \\
\text { - Heavily calcified occlusion } \leq 5 \mathrm{~cm} \\
\text { - Single popliteal stenosis }\end{array}$ \\
\hline Type C & $\begin{array}{l}\text { - Multiple stenosis or occlusions totaling }>15 \mathrm{~cm} \\
\text { with or without heavy calcification } \\
\text { - Recurrent stenosis or occlusions that need } \\
\text { treatment after two endovascular interventions }\end{array}$ \\
\hline Type D & $\begin{array}{l}\text { - Chronic total occlusion of CFA or SFA }(>20 \mathrm{~cm} \\
\text { involving popliteal artery) } \\
\text { - Chronic total occlusion of popliteal artery and } \\
\text { proximal trifurcation vessels }\end{array}$ \\
\hline \multicolumn{2}{|c|}{$\begin{array}{l}\text { CFA-common } \\
\text { femoral artery; } \\
\text { SFA-superficial } \\
\text { femoral artery }\end{array}$} \\
\hline TASC A & $\begin{array}{l}\text { Lesions that produce the best results and that should } \\
\text { be treated by endovascular route }\end{array}$ \\
\hline TASC B & $\begin{array}{l}\text { Lesions that produce sufficiently good results with } \\
\text { endovascular methods, so that this is preferred } \\
\text { approach, unless surgical revascularization is } \\
\text { required to treat other lesions in the same } \\
\text { anatomic area }\end{array}$ \\
\hline TASC C & $\begin{array}{l}\text { Lesions exhibiting superior long-term results with } \\
\text { surgery, so that endovascular methods should be } \\
\text { used only in patients at high surgical risk }\end{array}$ \\
\hline TASC D & $\begin{array}{l}\text { Lesions that do not produce good enough results } \\
\text { with endovascular methods to justify those as } \\
\text { primary treatment }\end{array}$ \\
\hline \multicolumn{2}{|c|}{ Ankle-brachial pressure index } \\
\hline \multicolumn{2}{|c|}{$\begin{array}{l}\text { Value }>1.3 \text { abnormal, non-compressible vessels } ;>1.0 \text { normal } ; \leq 0.9 \\
\text { peripheral artery disease, } \leq 0.6 \text { to } 0.8 \text { borderline, } \leq 0.5 \text { severe ischemia } \\
<0.4 \text { critical ischemia, limb threatened }\end{array}$} \\
\hline \multicolumn{2}{|l|}{ Restenosis: } \\
\hline $\begin{array}{l}\text { Significant } \\
\text { restenosis: }\end{array}$ & $\begin{array}{l}\text { More than } 50 \% \text { restenosis based on ultrasonography } \\
\text { derived velocity parameters (peak systolic } \\
\text { velocity ratio } 2.0 \text { ) }\end{array}$ \\
\hline \multicolumn{2}{|l|}{ Patency } \\
\hline Primary patency & $\begin{array}{l}\text { Defined as exempt from restenosis of the target } \\
\text { lesion during follow-up }\end{array}$ \\
\hline $\begin{array}{l}\text { Primary assisted } \\
\text { patency }\end{array}$ & $\begin{array}{l}\text { Defines durability of an intervention that failed initially } \\
\text { but not to the level of thrombosis and was retreated }\end{array}$ \\
\hline $\begin{array}{l}\text { Secondary } \\
\text { patency }\end{array}$ & $\begin{array}{l}\text { Patency of the target lesion after treatment of } \\
\text { (re)occlusion of the index lesion }\end{array}$ \\
\hline
\end{tabular}

Radiographic control was obtained with a Siemens Artis Zee Flat Panel Cath Lab (Siemens Healthcare Sector, Forchheim, Germany).

\section{Endovascular Procedure}

All procedures were performed by the same team of doctors at study site. The preferential approach was through the ipsilateral common femoral artery, with anterograde puncture, using a $6 \mathrm{~F}$ valved cook sheath (Cook Medical LLC, Bloomington USA). In case of impossibility of using the access route or crossing the target lesion, a retrograde access by puncturing one of the leg arteries (ATA/PTA) was chosen with 4F Cook micro puncture set and $5 \mathrm{~F}$ sheath. Through the pedal sheath, 5F MPA-1, and/or 5F cobra diagnostic catheters (Cordis Corporation, Warren, USA), diagnostic angiogram was obtained in fluoroscopic and digital subtraction mode (Fig. 1a, b).

Post lesion imaging, the occlusion were crossed by luminal or sub-luminal route, through a RadiofocusR (Terumo interventional Systems, Somerset, United States) hydrophilic guide wire (size, $0.035 " * 150 \mathrm{~cm}$ ) or V14 control wire and Rubicon 0.014 catheter (Boston Scientific Corporation, Marlborough, MA, USA). Predilatation of lesions was done prior to stent deployment. In all cases, the Supera (Abbott Laboratories, Abbott Park, USA) nitinol stent was deployed through pre-dilation. Post stent angiogram was obtained to check for flow across and distal to the lesion (Fig. 1c, d).

In contralateral lesions, after crossing with $150 \mathrm{~cm}$ RadiofocusR (Terumo interventional Systems, Somerset, USA) hydrophilic guide wire, the wire was exchanged for an Amplatz super stiff $300 \mathrm{~cm}$ wire for possible angioplasty. Subsequently, the Amplatz super stiff wire was exchanged for 0.018 wire for stent deployment.

Flow-limiting distal embolus was seen in 10 of these 86 cases, which could be aspirated with aspiration catheter. Postprocedural, local hemostasis was performed with manual compression for $30 \mathrm{~min}$ and patients were observed in ICU/ ward for possible contrast-related/hemodynamic complications.

\section{Post-operative Follow-up}

The follow-up initiated with outpatient evaluation, consisting of physical examination and ankle-brachial in$\operatorname{dex}(\mathrm{ABI})$ determination at 15, 30, 90, 180, and 365 days and at the end of 24 months after angioplasty. The control with Doppler ultrasound (USG-D) was performed at 30, 90 , and 180 days and at the end of 24 months after surgery, aimed at identifying significant restenosis ( $>50 \%$ restenosis based on USG-derived velocity parameters, peak systolic velocity ratio 2.0 ). Radiographs of the knee joint in posteroanterior (PA) and lateral views were performed at 30 and 180 days and at the end of 24 months, aimed at identifying stent fractures. 
Fig. 1 a Angiogram demonstrating occlusion of popliteal artery in a patient of critical limb ischemia with nonhealing forefoot ulcer. $\mathbf{b}$ Digital subtraction angiogram showing popliteal artery occlusion. c Post angioplasty and stenting with Supera demonstrating good flow across the popliteal artery. $\mathbf{d}$ Post angioplasty and stenting of popliteal artery demonstrating good distal flow.
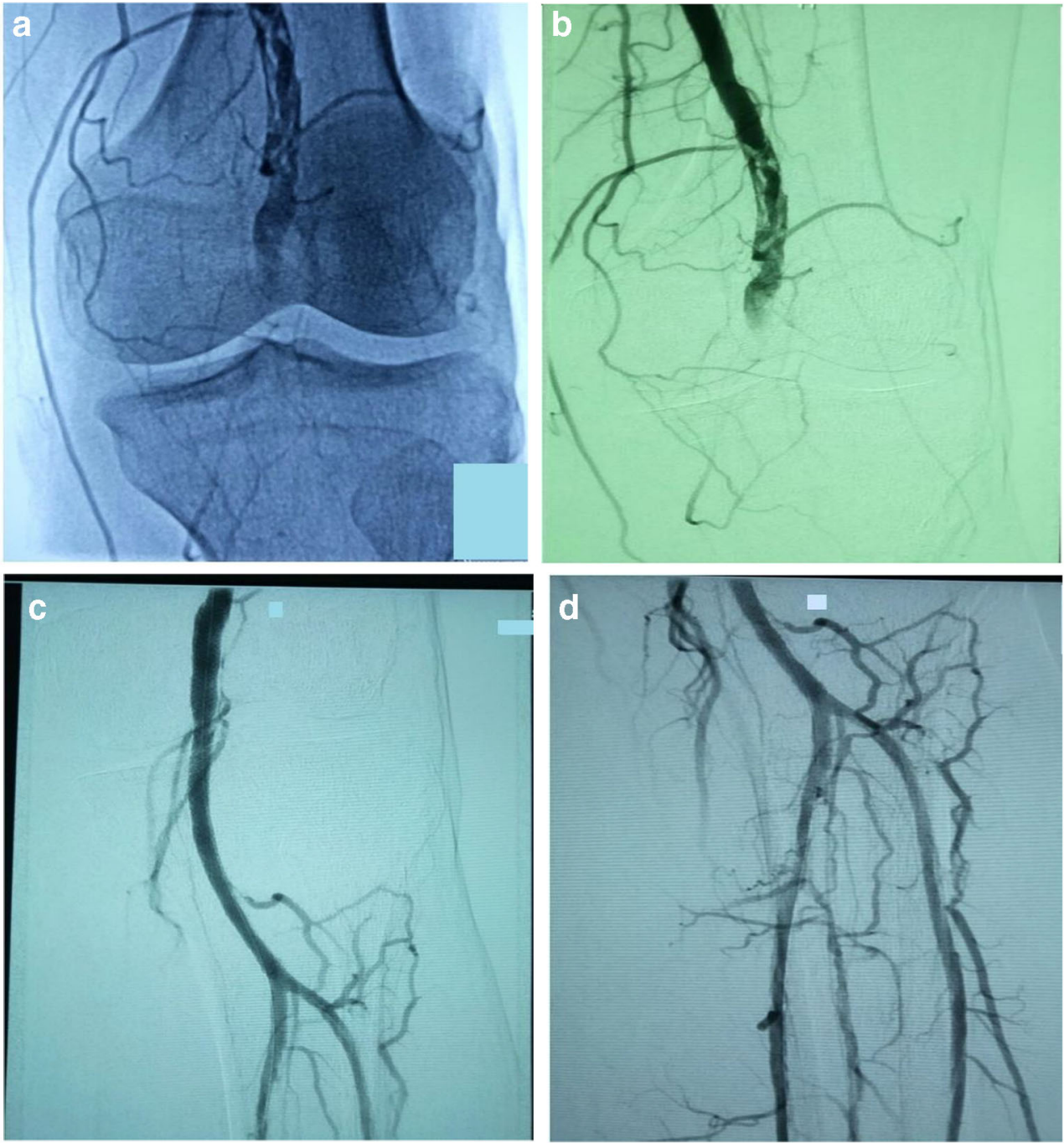

\section{Outcomes}

The analyzed outcomes were the following:

(1) Immediate technical success, when the target lesion was treated as planned, with residual lesion $<30 \%$ in the angiographic control;

(2) Primary patency, indicating an uninterrupted permeability after the revascularization procedure; and assisted primary patency, indicating cases with new percutaneous intervention applied, in order to prevent the impending occlusion or the progression of stenosis;

(3) Peri-operative morbidity/mortality, for complications and deaths recorded up to 30 days postoperatively;

(4) Major amputation: trans-femoral and trans-tibial amputations;

(5) Restenosis, for in-stent lesions $>50 \%$ detected with USG-D, with peak systolic velocity $>200 \mathrm{~cm} / \mathrm{s}$ or a pre- and post-stenosis rate $\geq 2$;
(6) Fractures, for disconnection or twisting of stent meshes; and

(7) Rate of limb salvage

All patients underwent physical examination, duplex ultrasound imaging, and radiographic imaging during the clinical follow-up period. One radiologist and one vascular interventionalist reviewed the results independently. The study was conducted according to the Declaration of Helsinki and approved by the hospital ethics committee.

\section{Statistical Analysis}

Data are shown as mean \pm SD for continuous variables or as percentages for dichotomous variables, unless otherwise noted. A $P<0.05$ was considered statistically significant. 


\section{Results}

Patients with symptomatic POAD treated with primary angioplasty (without employing other adjuvant methods of arterial unblocking) with stent implantation in popliteal arteries were eighty-six, and all were included in the study.

\section{Patient Demographics}

The age of the patients ranged from 42 to 78 years, of which 49 were male and 37 were female patients. Among them, 36 had a history of diabetes, and 41 patients had history of smoking. There was history of coronary artery disease in 38 patients, while claudication pain was complained by 22 of them. Patients with minor tissue loss were 64. Left leg was the most frequently treated limb (57.1\%) and all patients had trophic lesions with tissue loss.

\section{Characteristics of Lesions}

The lesions were classified into TASC B (50\%) and C (50\%) categories. Nearly, $71.4 \%$ of lesions were in the proximal segment of popliteal artery (P1), while in $28.6 \%$ of the cases, they were in the middle and distal segments, in equal proportion (P2 and P3). In 68 cases (79.06\%), the stents were implanted in previously occluded vessels through pre-dilation. In the runoff bed, majority of patients had only one patent artery (68.6\%) and the fibular artery was the most frequently observed. A mean of 2.2 arteries by treated limb was obtained. All cases allowed for target lesion revascularization, with technical success in $95 \%$. The average extent of lesion coverage was $138 \pm 24 \mathrm{~mm}$. All stents to treat the patients were used with a diameter of $5 \mathrm{~mm}$ and $5.5 \mathrm{~mm}$ (Fig. 2).

\section{Outcomes}

All the vessels could have successfully recanalized. The areas of more frequent stent landing were the distal segment of popliteal artery (P3) crossing the knee joint. Mean fluoroscopy time was $67 \pm 25 \mathrm{~min}$. Mean volume of iodinated contrast used was $74 \pm 38 \mathrm{~mL}$. Due to the impossibility of crossing the target lesion by the anterograde technique, distal retrograde access by the dorsalis pedis and PTA access from foot were performed in 36 and 12 cases, respectively. No complications concerning the puncture site were observed. The primary patency rate was $86.04 \%$ at 24 months ( 74 out of 86 patients). In 12 cases (13.96\%), a new balloon angioplasty had to be performed for treatment of ISR, yielding good result in 8 of them. The patency rate at the end of 15 months was $82.34 \%$.

\section{Follow-up}

The mean follow-up was 24 months. There were no intraoperative or procedure-related deaths and USG-D demonstrated proper flow across the stent (Fig. 3). Patients who died due to unrelated causes within 90 days of procedure were two $(2.32 \%)$. All-cause mortality rate was $2.32 \%$. The limb salvage rate was $100 \%$. There was no major amputation during the follow-up. However, one patient had forefoot amputation. Three patients developed trophic lesions; two of these lesions $(2.32 \%)$ were caused by in-stent stenosis on the 60th and 90th day of follow-up and treated by balloon dilation. The third injury occurred due to infectious complications resulting in minor amputation. The ABI increased from $0.4 \pm 0.15$ preoperatively to $0.8 \pm 0.13$ at the time of hospital discharge. There were no stent fractures documented by radiographs of the knee joint (Fig. 3).

\section{Discussion}

Substantially, severe atherosclerotic disease can cause popliteal artery occlusion. Thus, a thorough workup determining operative morbidity and mortality risks is necessary. Conservatively, patients with CAD and consequently increased morbidity and mortality would be treated using either conservative therapies or extreme limb amputation [5]. However, with developed technologies, a number of percutaneous endovascular procedures are being given to patients with PAD. Options of various stents (bare metal, biodegradable, drug-eluting, and covered) are available in order to yield better treatment and reduced risk of various complications associated with open surgical interventions [14].

The anatomical placement of popliteal artery causes increased biomechanical stress, thus impeding the management of atherosclerotic lesions in popliteal artery segment. Surgical interventions like grafts (either great saphenous vein, GSV, or prosthetic grafts) for treating popliteal artery occlusions involve occlusion bypass. The popliteal artery is accessed via medial thigh and calf incisions. Due to the anatomic location and the fact that the popliteal artery is not enclosed within muscle, this vascular patch faces significant mechanical stress during knee flexion/extension. Consequently, the management of atherosclerotic lesions in the popliteal artery segments is difficult and raises concerns regarding the suitability of stenting, followed by increased risk of stent fracture. Complex rotational, tensile, compressive, and stretching forces act simultaneously on the short arterial segment and the stent. Earlier, these lesions were treated by surgical grafting using autologous vein, with high primary and secondary patency rates of $63-75 \%$ and $80-83 \%$, respectively, after 5 years and a low peri-operative mortality of $1-3 \%$. However, these rates are accompanied by considerable peri-operative 
Fig. 2 USG Doppler study of popliteal artery with Supera stent, showing good flow across the stent during 6-month follow-up

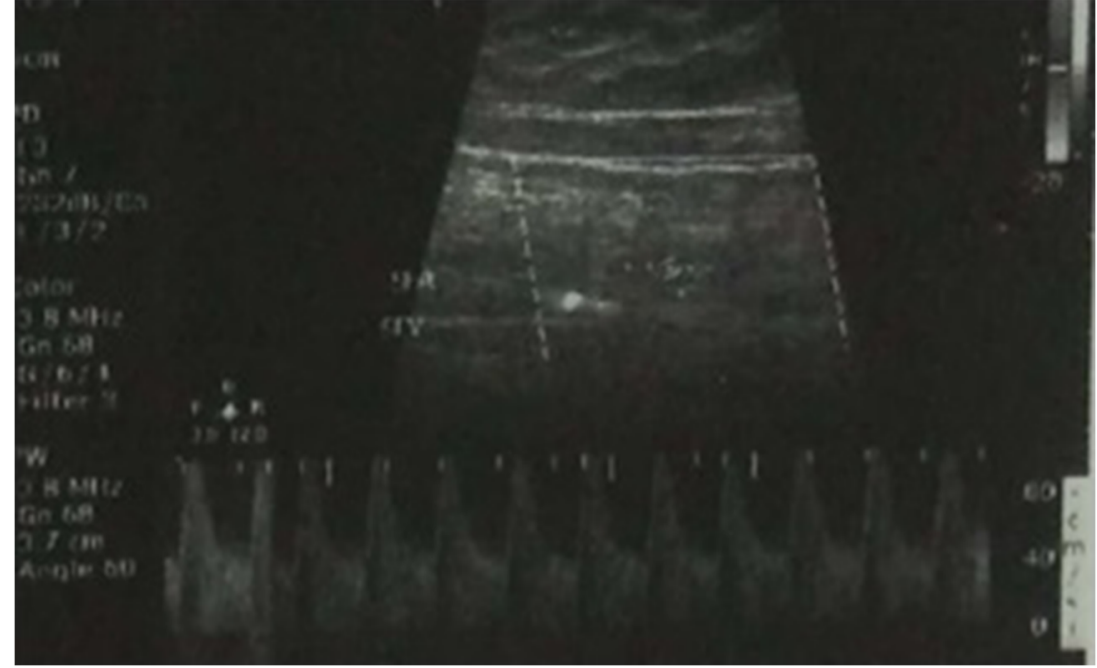

morbidity, as are the subsequent multiple surgical procedures and hospital readmissions [15].

As reviewed in a study [16-18], improved endovascular materials have led to increased number of minimally invasive procedures for the treatment of popliteal lesions [15]. Generally, balloon angioplasty or mechanical/laser arterectomy are the preferred choices for the treatment of arterial lesions behind the knee due to the lack of metallic devices capable of withstanding the forces exerted on this arterial segment [16-18].

RESILENT (Randomized Study Comparing the Edwards Self-Expanding LifeStent vs. Angioplasty Alone In Lesions Involving the SFA and/or Proximal Popliteal artery) was the first large study comparing treatment with balloon angioplasty vs. stenting in the femoropopliteal segment in patients with femoropopliteal occlusive lesions (that caused intermittent claudication) with length $<15 \mathrm{~cm}$ and diameter of the vessel

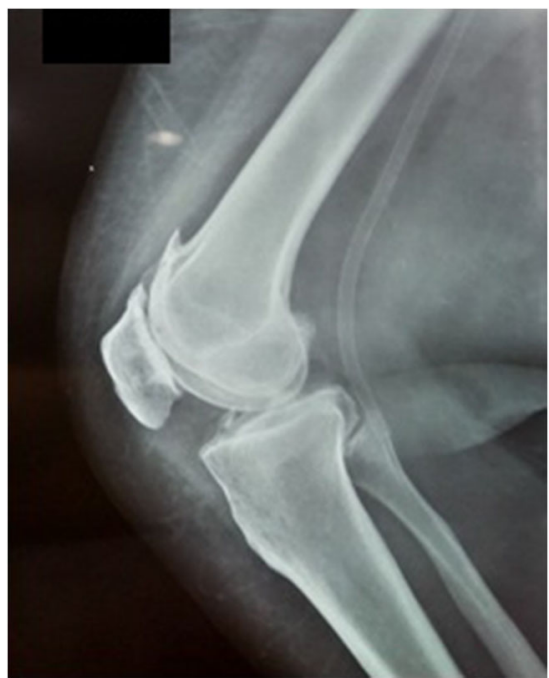

Fig. 3 X-ray of the right knee joint with a Supera stent in popliteal artery. There is no kinking or fracture of the stent with knee joint flexion between 4 and $6.5 \mathrm{~mm}$. The results showed the superiority of the LifeStentR (Bard Peripheral Vascular, Tempe, USA) over balloon angioplasty in the femoropopliteal segment [19]. The second phase allowed the treatment of more than one lesion, provided they did not exceed the length of $15 \mathrm{~cm}$. The primary patency of target vessel at 12 months was $80 \%$ vs. $38 \%$ for the LifeStentR vs. balloon angioplasty respectively [20].

Notwithstanding the efforts and advances, the efficacy of these techniques is limited. However, the Supera stent is designed like a braid of nickel-titanium alloy to withstand the mechanical stressors of the knee joint [21]. We conducted this study to analyze the safety and efficacy of nitinol Supera stent among Indian patients undergoing stent implantation for occlusion of popliteal artery.

Stent characteristics (diameter, length, flexibility, durability, and resistance to fracture) and lesion anatomic characteristics (location, degree of calcification) play significant role in choosing the stent. Stent implants in the popliteal artery have limitations including the insufficient radial force to maintain the vessel patency, and the possibility of folding and fracture of the device [14]. Stent fracture leads to restenosis and occlusions. Another study radiographically detected 64 fractures in 261 stents (24.5\%) used in the treatment of femoropopliteal lesions [22].

However, Supera stent is reportedly better in extreme mechanical stress and also for lesions of long lengths as well [5]. In SUPERB study [13, 23] among 325 patients with lower limb arterial obstructive diseases, it showed the primary patency with nitinol stent to be $78.9 \%(p<0.001)$ at 12 months, and primary patency by Kaplan-Meier analysis to be $86.3 \%$ at 12 months, and $99.2 \%$ patients freed from death, target lesion revascularization, or any amputation of the index limb after 30 days $[13,23]$.

In fact, several studies have showed better efficacy and safety with new nitinol stents. One such study (22) reported better flexibility, fracture prevention, and improved patency 
(primary patency rates of $83.5 \%$ and $78.6 \%$, at 6 and 12 months, respectively) with the Supera helica interwoven nitinol stent [8]. In another study, Durability-200 [8] observed that primary patency after 6 and 12 months of implantation of stents in the femoropopliteal segment to be $85.4 \%$ and $64.8 \%$, respectively, patients [24]. Another study [25] reported a primary patency rate of $82 \%$ and $100 \%$ limb salvage rate. In our study among patients with arteriographic lesions of TASC B and $\mathrm{C}$ categories, the primary patency and assisted primary patency were $85.7 \%$ and $92.8 \%$, respectively.

Most studies have included patients with claudication, critical limb ischemia, rest pain, or tissue loss or calcification, and stenting has been studied among elderly patients [3, 5, 13, 23]. Like ours, some studies have also not reported any stent fractures $[3,5,13,23]$.

However, a fracture of Supera stent can lead to complete loss of integrity making it collapse [26].

Another study among patients with symptomatic atherosclerotic disease of popliteal artery also shows that after a mean follow-up of 16.5 months, the primary patency rates were $89.6 \%$, and the primary assisted patency rates were 93.8\% ; and the in-stent restenosis was associated with age $>$ 75 years, female gender and TASC-II D lesions, and not with implantation defects [27].

Failure of patency or occurrence of ADRs has been limited in the earlier studies. Reasons for failure include stent intussusceptions, compromised inflow or outflow, lesion length, wrong size of the stent, and compression or elongation during deployment [13, 23].

Another study has, however, reported eight major amputations and overall mortality of $11.6 \%$ during study period [5].

Our study reported similar limb salvage rate post 24 month follow-up; however, the primary patency and assisted primary patency were $85.7 \%$ and $92.8 \%$, respectively, among patients with critical ischemia of Rutherford classes 5 and 6, and in arteriographic lesions of TASC B and C categories, compared with patency rates obtained during other studies. During the clinical follow-up, ABI improved from $0.4 \pm 0.15$ preoperatively to $0.8 \pm 0.13$ at the time of discharge. Additionally, trophic lesions improved in $78.6 \%$ cases.

The measurement of ABI has been overestimated due to high prevalence of DM in our population (64.3\%), considering that the predominance of arterial calcifications in the distal portions of leg arteries of diabetic patients overestimates the measurement of the index.

However, smaller population, heterogeneous group of segments treated in the popliteal artery, short follow-up period, and the lacking established algorithm for clinical follow-up might have influenced the results of this study. Further studies are required to establish the superiority of Supera stent over other stents in popliteal arteries, with specific mention of the segments of popliteal artery being treated and having a longer follow-up period.

\section{Conclusions}

Popliteal artery stenting is emerging as a viable option in treatment of disabling claudication and limb ischemia. Supera stent demonstrated safety and efficacy in the management of popliteal artery disease. Comparative trials of the Supera stent system directly with other stent systems as well as to angioplasty alone are needed, to establish the superiority of Supera interwoven nitinol stent system.

\section{Compliance with Ethical Standards}

Institutional Review Board Approval The study involves using Supera stent, which is an FDA-approved product. The stent has been used in a manner it is intended to be used. Hence, Institutional Review Board committee approval was not required.

Open Access This article is licensed under a Creative Commons Attribution 4.0 International License, which permits use, sharing, adaptation, distribution and reproduction in any medium or format, as long as you give appropriate credit to the original author(s) and the source, provide a link to the Creative Commons licence, and indicate if changes were made. The images or other third party material in this article are included in the article's Creative Commons licence, unless indicated otherwise in a credit line to the material. If material is not included in the article's Creative Commons licence and your intended use is not permitted by statutory regulation or exceeds the permitted use, you will need to obtain permission directly from the copyright holder. To view a copy of this licence, visit http://creativecommons.org/licenses/by/4.0/.

\section{References}

1. Maleckis K, Anttila E, Aylward P, Poulson W, Desyatova A, MacTaggart J, Kamenskiy A (2018) Nitinol stents in the femoropopliteal artery: a mechanical perspective on material, design, and performance. Ann Biomed Eng 46:684-704

2. Lehto S, Niskanen L, Suhonen M, Rönnemaa T, Laakso M (1996) Medial artery calcification. A neglected harbinger of cardiovascular complications in non-insulin-dependent diabetes mellitus. Arterioscler Thromb Vasc Biol 16:978-983

3. Rousseau HP, Raillat CR, Joffre FG, Knight CJ, Ginestet MC (1989) Treatment of femoropopliteal stenoses by means of selfexpandable endoprostheses: midterm results. Radiology 172:961964

4. Al-Nouri O et al (2012) Failed superficial femoral artery intervention for advanced infrainguinal occlusive disease has a significant negative impact on limb salvage. J Vasc Surg 56:106-111

5. Montero-Baker M, Ziomek GJ, Leon L, Gonzales A, Dieter RS, Gadd CL, Pacanowski JP Jr (2016) Analysis of endovascular therapy for femoropopliteal disease with the Supera stent. J Vasc Surg 64:1002-1008

6. Schlager O, Dick P, Sabeti S, Amighi J, Mlekusch W, Minar E, Schillinger M (2005) Long-segment SFA stenting - the dark sides: in-stent restenosis, clinical deterioration, and stent fractures. J Endovasc Ther 12:676-684

7. Darling JD, McCallum JC, Soden PA, Korepta L, Guzman RJ, Wyers MC, Hamdan AD, Schermerhorn ML (2017) Results for primary bypass versus primary angioplasty/stent for lower extremity chronic limb threatening ischemia. J Vasc Surg 66:466-475 
8. Chang C-H, Lin J-W, Hsu J, Wu L-C, Lai M-S (2016) Stent revascularization versus bypass surgery for peripheral artery disease in type 2 diabetic patients-an instrumental variable analysis. Sci Rep 6:37177

9. Bishu K, Armstrong EJ (2015) Supera self-expanding stents for endovascular treatment of femoropopliteal disease: a review of the clinical evidence. Vasc Health Risk Manag 11:387-395

10. US FDA. Summary of safety and effectiveness data of Supera stent

11. Tosaka A, Soga Y, Iida O, Ishihara T, Hirano K, Suzuki K, Yokoi H, Nanto S, Nobuyoshi M (2012) Classification and clinical impact of restenosis after femoropopliteal stenting. J Am Coll Cardiol 59: $16-23$

12. Virga V, Stabile E, Biamino G, Salemme L, Cioppa A, Giugliano G, Tesorio T, Cota L, Popusoi G, Pucciarelli A, Esposito G, Trimarco B, Rubino P (2014) Drug-eluting balloons for the treatment of the superficial femoral artery in-stent restenosis: 2-year follow-up. JACC Cardiovasc Interv 7:411-415

13. Garcia LA, Rosenfield KR, Metzger CD, Zidar F, Pershad A, Popma JJ, Zaugg M, Jaff MR, on behalf of the SUPERB investigators (2017) SUPERB final 3-year outcomes using interwoven nitinol biomimetic supera stent. Catheter Cardiovasc Interv 89: 1259-1267

14. Simard T, Russo JJ, O'Brien ER, Hibbert B (2018) Coronary stenting. in Textbook of catheter-based cardiovascular interventions 623-639. Springer International Publishing, Cham. https:// doi.org/10.1007/978-3-319-55994-0 38

15. Spiliopoulos S, Kamarinos NV, Brountzos E (2019) Current evidence of drug-elution therapy for infrapopliteal arterial disease. World J Cardiol 11:13-23

16. Herzog A, Oszkinis G, Planer D, Ziaja K, Kruszyna $Ł$, Stanisić MG, Ziaja D, Ishaaya AA, Kuczmik W (2017) Atherectomy using a solid-state laser at $355 \mathrm{~nm}$ wavelength. J Biophotonics 10:12711278

17. Karnabatidis D, Spiliopoulos S, Katsanos K, Siablis D (2012) Below-the-knee drug-eluting stents and drug-coated balloons. Expert Rev Med Devices 9:85-94

18. Katsanos K, Spiliopoulos S, Krokidis M, Karnabatidis D, Siablis D (2012) Does below-the-knee placement of drug-eluting stents improve clinical outcomes? J Cardiovasc Surg 53:195-203

19. Laird JR, Katzen BT, Scheinert D, Lammer J, Carpenter J, Buchbinder M, Dave R, Ansel G, Lansky A, Cristea E, Collins TJ, Goldstein J, Jaff MR, for the RESILIENT Investigators
(2010) Nitinol stent implantation versus balloon angioplasty for lesions in the superficial femoral artery and proximal popliteal artery. Circ Cardiovasc Interv 3:267-276

20. Laird JR et al (2012) Nitinol stent implantation vs. balloon angioplasty for lesions in the superficial femoral and proximal popliteal arteries of patients with claudication: three-year follow-up from the RESILIENT randomized trial. J Endovasc Ther 19:1-9

21. Chan YC, Cheng SW, Ting AC, Cheung GC (2014) Primary stenting of femoropopliteal atherosclerotic lesions using new helical interwoven nitinol stents. J Vasc Surg 59:384-391

22. Scheinert D, Scheinert S, Sax J, Piorkowski C, Bräunlich S, Ulrich M, Biamino G, Schmidt A (2005) Prevalence and clinical impact of stent fractures after femoropopliteal stenting. J Am Coll Cardiol 45: 312-315

23. Garcia L, Jaff MR, Metzger C, Sedillo G, Pershad A, Zidar F, Patlola R, Wilkins RG, Espinoza A, Iskander A, Khammar GS, Khatib Y, Beasley R, Makam S, Kovach R, Kamat S, Leon LR Jr, Eaves WB, Popma JJ, Mauri L, Donohoe D, Base CC, Rosenfield K, SUPERB Trial Investigators (2015) Wireinterwoven nitinol stent outcome in the superficial femoral and proximal popliteal arteries. Circ Cardiovasc Interv 8(5):e000937

24. Bosiers M, Deloose K, Callaert J, Moreels N, Keirse K, Verbist J, Peeters P (2011) Results of the Protégé EverFlex 200-mm-long nitinol stent (ev3) in TASC C and D femoropopliteal lesions. J Vasc Surg 54:1042-1050

25. Kickuth R, Keo HH, Triller J, Ludwig K, Do D-D (2007) Initial clinical experience with the 4-F self-expanding XPERT stent system for infrapopliteal treatment of patients with severe claudication and critical limb ischemia. J Vasc Interv Radiol 18:703-708

26. San Norberto EM, Fuente R, Flota CM, Taylor JH, Vaquero C (2017) Impact of implantation defects on intermediate outcome of Supera stent for popliteal artery stenosis. Ann Vasc Surg 41:186195

27. Myint M, Schouten O, Bourke V, Thomas SD, Lennox AF, Varcoe RL (2016) A real-world experience with the Supera interwoven nitinol stent in femoropopliteal arteries. J Endovasc Ther 23:433441

Publisher's Note Springer Nature remains neutral with regard to jurisdictional claims in published maps and institutional affiliations. 